\section{Estudio de la lengua popular} utilizada por hablantes de Managua, Nicaragua: perspectiva lexicográfica Study of the popular language used by speakers from Managua, Nicaragua: lexicographic perspective
Francis Mendoza Morán Universidad Nacional Autónoma de Nicaragua, Managua menmoran@hotmail.com

(C) UNAN-Managua Recibido: Noviembre 2016 Aprobado: Diciembre 2016

\section{RESUMEN}

Los objetivos propuestos de esta investigación permitieron explorar y aplicar parte del cuestionario del Proyecto de estudio sociolingüístico del español de España y América (PRESEEA) en varias zonas de Managua. Las entrevistas fueron escuchadas varias veces para dar paso a la identificación de lemas y frases que estuvieran en el nivel sociocultural de la lengua popular. Después se pasó a la etapa de la estructuración del corpus lexicográfico. Seguidamente los resultados fueron argumentados desde la perspectiva lexicográfica, destacando informaciones, tales como: gramatical, pragmática, nivel de lengua y algunas locuciones. Este trabajo es un aporte para el fortalecimiento de los estudios sobre la descripción léxico-semántica del español hablado actualmente en Nicaragua.

\section{SUMMARY}

The proposed objectives of this research allowed to explore and apply part of the questionnaire of the Sociolinguistic Study Project of Spanish from Spain and America (PRESEEA) in several areas of Managua. The interviews were heard several times to give way to the identification of slogans and phrases that were in the sociocultural level of the popular language. Then he went to the stage of structuring the lexicographic corpus. Then the results were argued from the lexicographic perspective, highlighting information, such as: grammatical, pragmatic, language level and some phrases. This work is a contribution to the strengthening of studies on the lexical-semantic description of Spanish currently spoken in Nicaragua.

\title{
Metodología de la investigación
}

La presente investigación se vincula directamente con un enfoque léxico-semántico1, puesto que se recopila información del léxico de algunos pobladores de los barrios de Managua. El enfoque de esta investigación es cuantitativo y cualitativo, porque se analizaron y describieron rasgos característicos de los fenómenos lexicográficos compilados. También es de tipo descriptiva, porque caracteriza y describe el uso de la lengua popular en los hablantes entrevistados.

\footnotetext{
1 Debe aclararse que esta distribución de los hablantes facilitó el análisis, pero aunque se hayan considerado tres variables sociales, estas no fueron objeto de estudio del trabajo. Es decir, el enfoque no fue sociolingüístico.
} 
La población estuvo conformada por los habitantes de la capital de Nicaragua, que como se dijo anteriormente, es de aproximadamente 1,004,950 habitantes. No obstante, no se pudo aplicar el instrumento de campo a todos ellos. El tipo de muestreo ${ }^{2}$ aplicado fue no probabilístico por cuotas con afijación uniforme. Esta permite fácil comparación estadística entre las cuotas internas de la misma muestra.

En cuanto, a la técnica de recolección y análisis de datos, al identificar las características de los habitantes entrevistados, se aplicaron elementos lexicográficos a cada lema y frase seleccionada. Con relación a la entrevista, esta se retomó del cuestionario del PRESEEA. Sin embargo, se realizaron algunas adaptaciones a la realidad del capitalino nicaragüense.

Entre los métodos generales que se aplicaron están:

a) Análisis: A través de este se llegaron a determinadas conclusiones de los diferentes planteamientos teóricos y prácticos utilizados en la investigación.

b) Síntesis: Después que se realizó el análisis respectivo de los datos, este método permitió concluir las ideas fundamentales del estudio.

c) Comparativo: Se aplicó al comparar cada lema y frase con el DEN (2009) y DLE (2014). Esto accedió a que la semántica expuesta en el corpus, sea la expresada por los autores de este estudio.

d) Gramatical: Se manifestó en la información gramatical de cada artículo lexicográfico. Como todas, se determinó a través de la documentación expuesta.

e) Sintáctico: Se utilizó en la documentación presentada en el glosario (uso de la palabra o frase en la oración). En cada ejemplo oracional, se observó el tipo de estructura sintáctica.

f) Semántico: Se aplicó al momento de definir cada lema y frase estudiada, según contexto oracional.

En cuanto a los métodos específicos, se emplearon:

a) Descripción y aplicación: La descripción permitió apropiarse de las características del lugar donde se realizaron las entrevistas. Cabe destacar, que se realizó una visita previa a la comunidad para su aplicación.

b) Entrevista: Se realizaron preguntas previamente planificadas, abiertas a la discusión efectiva, con el propósito de abordar conceptos y aplicación, de esta forma permitió la recopilación de los datos en el que se ajusta el tema. Como se explicó anteriormente, el instrumento de investigación aplicado en esta investigación, fue con base al PRESEEA. Se le hicieron algunos ajustes en cuanto a la forma de preguntar, es decir se entró en empatía con el hablante para lograr el objetivo propuesto. Así, se hicieron interrogantes como:

Módulo: EL TIEMPO (Según el PRESEEA este módulo o parte del cuestionario refiere al clima).

1. ¡Qué calor/frío ha hecho hoy! A mí no me gusta el verano/invierno ¿Tú (Vos-Usted) cuál prefieres?

2. Este año ha hecho más calor/ha llovido más que el año pasado, ¿verdad?

2 Este tipo de muestreo permite asignar igual número de informantes a cada una de esas cuotas. 
3. Yo pienso que está cambiando el tiempo, al menos por esta zona, ¿tú (Vos-Usted) qué opinas? ¿Por qué será?

4. ¿Recuerdas (Vos-Usted) el tiempo que hizo el año pasado por estas fechas, Iluvia, frío, viento, tormentas...? ¿Y en invierno/verano?

5. Dicen que está cambiando el clima en la tierra ¿qué crees (Vos-Usted) que va a pasar si deja de llover y continúa la sequía en los próximos años?

Estas se realizaron con mucha discreción y tacto. Se les hizo una visita previa y se procuró entrar en confianza con ellos.

Las grabaciones tuvieron una duración de entre 6 a 10 minutos. Después de ser escuchadas, se identificaron aquellos lemas y frases que se ubican en el nivel de lengua popular. Esto favoreció la elaboración del corpus lexicográfico, es decir el glosario 3 . Cabe destacar, que cada una de las voces estudiadas fueron contrastadas con el DEN (2009) y DLE (2014). Así, las definiciones expuestas fueron redactadas por la autora de acuerdo al contexto oracional en que fue utilizada.

Plan de tabulación y análisis

Este permitió que los datos se ordenaran y fueran representados en gráficas respectivas, con las distintas informaciones lexicográficas que llevaron de la mano hacia el análisis cuantitativo y cualitativo de la investigación.

Para la elaboración del artículo lexicográfico (entradas) se determinó seguir las siguientes características:

a) Lema: este se indica al inicio de la entrada y se presenta en negrita.

comelón. adj. desp. Referido a alguien, que es homosexual. ¿Cómo son tus amigos? - Mis amigos son trolazo y comelones.

b) Información gramatical: aparece detallada, según la utilización sintáctica identificada.

jacqueline. Adv. Ya, en este momento. No sabes vos como son las cosas que pasan en la vida, Jaqueline.

c) Información semántica: es la significación contextual de los lemas o locuciones compiladas.

torozón. m. Sensación de nudo en la garganta que impide expresarse. Aquí siento un torozón/ en la garganta. Canción: "La misa campesina".

d) Información pragmática: se ubicaron después de la información gramatical.

tayacán. (Del náhuatl teyacanqui, director).

m. hiperb. Hombre fuerte y robusto que enfrenta diferentes tareas. Mientras su mamá se penqueya en la rebusca, / quincho se faja como todo un guayacán. Canción: "Quincho Barrilete".

3 Este aparece ubicado en el análisis de los datos 
e) Documentación: esta queda fundamentada en los ejemplos oracionales que aparecen al final del artículo lexicográfico. Estos se basan en el uso del lenguaje oral y escrito .

bajín. m. fest. Comida que se establece en un tiempo. El bajín de ayer fue pollo con papa.

f) Observación: es la parte que puede o no aparecer al final de la entrada. Esto dependerá de las diferentes informaciones que se expongan.

pachita. f. dim. Envase plástico popular para llevar licor. Simón bajar Con santo domingo desde la sierra Con mi pachita de Guaro. Obs.: generalmente esto se hace durante Alguna fiesta religiosa

g) Locuciones: presentan una clasificación de acuerdo a la intención semántica de su estructura.

sebo. (Del lat. Sebum). // serenado. loc. adj. [Referido a un tipo de ungüento], que quita cicatrices. Este agujero tremendo /que mi brazo perforó/ No es como dice la gente/Que es un hoyo de inyección / Me lo pegó un alistado/ Dicen que por casualidad/ Ni con sebo serenado / Se me ha podido borrar. Canción: "Chinto Jiñocuago".

\begin{tabular}{|l|l|}
\hline \multicolumn{1}{|c|}{ AbreviaturaS } & ignificado \\
\hline adj & adjetivo \\
\hline adv & adverbio \\
\hline apóc & apócope \\
\hline afect & Afectivo, va \\
\hline ár & árabe \\
\hline aum & aumentativo \\
\hline desp & despectivo \\
\hline dim & diminutivo \\
\hline etc & etcétera \\
\hline entrev & entrevista \\
\hline f & femenino \\
\hline
\end{tabular}


Irónicamente, el personaje del cuento que dice apertrecharse de una poesía según la expectativa de la empresa redentora aparecería más bien como "el infeliz", "un pobre diablo" condenado a muerte por efectos de la injusticia terrenal. En esta ocasión de "la noche sombría" "en el palacio había festín", derroche de opulencia, placer y brindis, es decir, se celebraba el triunfo del mal sobre el bien. En este tipo de discurso la imagen del gran vacío permite a las voces expresar de cierto modo, el grado de conciencia por participar en la armonía del mundo.

En el cuento ¿Por qué? el enunciador (narrador) alude a la manera en que la sociedad se ha deshumanizado y ha echado los diversos valores éticos y morales por la borda. El narrador disconforme y marginal es Juan Lanas y se dirige a Dios como narratario (-iOh, Señor!, el mundo anda muy mal (...) para pedirle pronta justicia. Este narrador realiza un inventario de situaciones y actos que pone en entredicho los ámbitos sociales, políticos, religiosos, administrativos, morales, entre otros, de un mundo que se resquebraja. El factor de disconformidad conduce al narrador a imprimirle un tono increpante y emotivo a su discurso, y de este modo acentúa la visión escatológica de carácter cronológico, es decir, de aquello que está por suceder (El siglo que viene verá la mayor de las revoluciones que han ensangrentado la tierra- dice). Se trata, por tanto, de un enunciador (narrador-personaje) que asume la actitud de un líder social inspirado en el discurso y tono apocalípticos:

Pero los anuncios del cataclismo están ya a la vista de la humanidad y la humanidad no los ve; lo que verá bien será el espanto y el horror del día de la ira. No habrá fuerza que pueda contener el torrente de la fatal venganza. Habrá que cantar una nueva marsellesa que como los clarines de Jericó destruya la morada de los infames. El incendio alumbrará las ruinas. El cuchillo popular cortará cuellos y vientre odiados; las mujeres del populacho arrancarán a puños los cabellos rubios de las vírgenes orgullosas; la pata del hombre descalzo manchará la alfombra del opulento; se romperán las estatuas de los bandidos que oprimieron a los humildes; y el cielo verá con temerosa alegría, entre el estruendo de la catástrofe redentora, el castigo de los altivos malhechores, la venganza suprema y terrible de la miseria borracha

En "Salutación del optimista" de Cantos de vida y esperanza lo apocalíptico se compenetra de la situación depresiva dejada por las pérdidas de las colonias de España en América, en tanto emerge la voz de la autoconciencia del enunciador fraterno y augural, que pretende armonizar el estado emocional y de fe mediante los "nuevos himnos" para incidir en el cambio. Es decir, advierte de la presencia de Dios para comenzar nuevos tiempos. Las imágenes apocalípticas, tanto mesiánicas como fatales, van surgiendo como contrapuntos entre el presente y el futuro esperanzador, a fin de sobreponerse a las heridas dejadas por la fragmentación de la hispanidad. De este modo, el texto alegoriza tanto el mal como el bien: Retrocede el olvido, retrocede engañada la muerte; / se anuncia un reino nuevo, feliz sibila sueña. Es notoria, además, la actitud imperativa de esta voz al elevar su tono, mediante el cual usurpa la instancia de autoridad: Abominad la boca que predice desgracias eternas, / abominad los ojos que ven sólo zodíacos funestos, / abominad las manos que apedrean las ruinas ilustres / o que la tea empuñan o la daga suicida. Estos versos que en un primer nivel de lectura alientan para abandonar lo dañino, aquello que puedan decir los falsos profetas, son opuestos al espíritu de fe y esperanza. Son estructuras poéticas que se compenetran del imaginario apocalíptico desde otro nivel especulativo: boca (símbolo de profecía), ojos (percepción de la sabiduría), manos (símbolo de poder), tea (equivalente a fuego, asociado a la presencia de Dios), daga (equivalente a la espada, simbolizando así la justicia).

5 Veamos al respecto este fragmento: "El Ángel del Señor a Juicio llama/ al Pasado, al Presente/ y al Porvenir. El eco se derrama, / y el abismo se inflama/ al tronar la palabra omnipotente". 
La percepción de pérdida o fragmentación de la hispanidad, no obstante, induce al enunciador a expresar las razones por las cuales se pronuncia, haciéndolo de forma impersonal, como pretendiendo objetividad, mediante imágenes impactantes de una fuerza sobrenatural que mimetiza el evento catastrófico:
Siéntense sordos impetus en las entrañas del mundo,
la inminencia de algo fatal hoy conmueve la Tierra;
fuertes colosos caen, se desbandan bicéfalas águilas,
$y$ algo se inicia como vasto social cataclismo
sobre la faz del orbe (...)

La conciencia del enunciador queda registrada también a modo de incidencia en los demás, con la esperanza de que Dios venga a reinar en quienes lo escuchan, pues traerá cambios radicales, como refiriendo la fundación de la Nueva Jerusalén:

La latina estirpe verá la gran alba futura, en un trueno de música gloriosa, millones de labios saludarán la espléndida luz que vendrá de Oriente, Oriente augusto en donde todo lo cambia y renueva Y así sea Esperanza la visión permanente en nosotros, iÍnclitas razas ubérrimas, sangre de Hispania fecunda!

Se trata de que el hablante poético pluraliza su experiencia personal del yo al referir "la visión permanente en nosotros". En cambio, en el poema "Cantos de esperanza", el hablante se hace eco de los acontecimientos bélicos y sus efectos de la guerra ruso-japonesa acaecida entre 1904 y 1905 . En correspondencia con este hecho histórico el texto introduce en su estrofa inicial el evento que justifica el motivo apocalíptico acudiendo al recurso de la alegoría de la muerte, mediante estructuras como "gran vuelo de cuervos", "mancha", "amagos de peste", "asesinan". Sumada a esta alegoría está la interrogante retórica que introduce en el poema el síntoma de la presencia del mal en la tierra o, dicho de otra manera, la secularización queda expresada en la desorientación religiosa, que el hablante poético percibe desde su atalaya espiritual: ¿Ha nacido el apocalíptico Anticristo?

De la estrategia retórica el enunciador va a pasar a la forma impersonal e imaginada por el cuerpo social (Se han sabido presagios y prodigios se han visto), para después convertir esta versión en una formulación que se va a plegar a la individual del hablante, obteniendo así una primera conclusión: Y parece inminente el retorno del Cristo. Esta voz intermediaria luego apostrofa y se pronuncia a favor de la redención urgente ante el enunciatario: ¡Oh, Señor Jesucristo! por qué tardas, qué esperas/ para tender tu mano de luz sobre las fieras/ y hacer brillar al sol tus divinas banderas! Se trata de la restauración profunda, no en términos de la violencia trágica sino del cambio hondamente espiritual y pacificador:

Ven, Señor, para hacer la gloria de ti mismo

ven con temblor de estrellas y horror de cataclismo,

ven a traer amor y paz sobre el abismo.

El enunciador, en su estilo reiterativo, adquiere un nuevo estatus al contribuir a subsanar ese vacío espiritual, pues al dirigirse al enunciatario (Jesucristo), al final se le presenta como una ofrenda. Este hablante se convertirá en incensario, es decir, medio o instrumento de purificación, a modo de ángel o sacerdote ante el trono de Dios: 
Y tu caballo blanco, que miró el visionario, pase. Y suene el divino clarín extraordinario. Mi corazón será brasa de tu incensario.

En el poema "Mientras tenéis, ¡oh negros corazones!" se nota el enfrentamiento entre fuerzas contrarias manifiestas entre el vulgo hostil y los artistas incomprendidos. De ahí que cuando el enunciador asocia la imagen de Cristo a la figura del "pensador" y "divino" construye la relación solidaria con los artistas, a costa de la sacralización en los siguientes términos: Pero tu carne es pan y tu sangre es vino, refiriéndose a "Shakespeare pobre" y a "Cervantes manco". Este enunciador, además, va a mostrar una tonalidad de advertencia al percibir las injusticias con los artistas:

Un gran Apocalipsis horas futuras llena

¡Ya surgirá vuestro Pegaso blanco!

Se trata no sólo de que la literatura asuma un discurso de la representación del apocalipsis como manifestación disconforme de un tiempo presente, sino también de una justicia en términos de la recepción artística, ya que el "Pegaso blanco" está inmerso en un sentido de ironía, que advierte una deuda simbólica.

En "Letanía a nuestro señor Don Quijote" el hablante se dirige a este personaje para que escuche los ruegos de intercesión por "nosotros", por estar con el alma a tientas, con la fe perdida, / llenos de congojas y faltos de sol. De esta modo, la letanía que conmemora el III centenario de El Quijote de Cervantes, al sacralizar al personaje y mundanizar lo sagrado, deja al hablante relativamente distanciado de Dios, y su vínculo no es directo, sino que necesita de un mediador o intercesor: Ruega generoso, piadoso, orgulloso; / ruega casto, puro, celeste, animoso; / por nos intercede, suplica por nos, / pues casi ya estamos sin savia, sin brote, / sin alma, sin vida, sin luz, sin Quijote, / sin pies y sin alas, sin Sancho y sin Dios. Esta inversión la había hecho notar Pedro Salinas, al advertir que la letanía es "una canonización poética de un nuevo santo hispánico. Santo patrono del idealismo y la heroicidad moral" (Citado por Ruiz Barrionuevo, 2002, p. 110).

El poema "A Colón" de El canto errante, desarrolla el tema de la falta de trascendencia o fracaso de las repúblicas del continente americano, en su condición degradada (por guerras, transculturación y otras formas de violencia), dejando la impresión de lucha entre Caínes y Abeles; esta percepción se acentúa con la versión del enunciador colonizado: Un desastroso espíritu posee tu tierra / donde la tribu unida blandió sus mazas, / hoy se enciende entre hermanos perpetua guerra / se hieren y destrozan las mismas razas. En la lectura del poema nos encontramos con que el tono del hablante poético, que al inicio le había gritado ;Desgraciado Almirante; después aparece solicitando a este personaje histórico ya rebajado de su heroísmo ("pobre Almirante"), que interceda por la "América histérica" para no merecer el castigo divino:

Duelos, espantos, guerras, fiebre constante en nuestra senda ha puesto la suerte triste: ¡Cristóforo Colombo, pobre Almirante, ruega a Dios por el mundo que descubriste! 
Este enunciador individual luego se pluraliza, al referir La cruz que nos llevaste padece mengua, asimismo contribuyen a la pluralización las referencias a América como colectividad. En cambio, en el cierre del poema "Momotombo" la figura de Cristóforo Colombo se presenta emparejada con la de Víctor Hugo y del volcán Momotombo. Ambos están concebidos como montañas habitadas por el fuego de Dios, porque uno de ellos escuchó el rugido del coloso y el otro lo cantó, desplazando de esta manera el sentido de majestuosidad y grandeza del volcán hacia la imagen de ambos personajes. Y aunque el discurso cuestiona que se haya olvidado la trascendencia del hombre y su cultura, la instancia del yo se dirige únicamente al tú (Momotombo). En estos pasajes del poema es notorio el recurso del pathos apocalíptico, pues la emotividad del enunciado contribuye a destacar el acercamiento crítico de la lucha de fuerzas contrarias:

¡Hacia el misterio caen poetas y montañas

y romperás el cielo de cristal

cuando luchen sonando de Pan las siete cañas

y la trompeta del Juicio Final!

Este nuevo elemento simbólico (el dios Pan) es la figura mitológica y mundana de grandes pasiones que hacía sonar agradables entonaciones con su flauta de siete cañas, dando la impresión de siete cielos y, según el sentido del texto, se enfrenta ante la justicia final. La relación con el texto bíblico es que Los siete ángeles de las siete trompetas se prepararon para tocar, y después de cada sonada emergía una acción o sucesos que afectaban al ser humano.

En "Salutación al Águila" el tema plantea la aceptación de la presencia de Estados Unidos, simbolizado en el Águila, sólo con la condición de que sea en son de paz y de influencia en el progreso de los países de América Hispana. Hay en el texto un simbolismo mítico-religioso, asumiendo que en el cristianismo el águila es símbolo del mensajero celestial y de resurrección. Por otra parte, el águila jupiteriana es la tempestad teriomórfica, que sustituye con animales el protagonismo de las historias narradas. En ese sentido leamos la estrofa:

Por algo eres la antigua mensajera jupiteriana

por algo has presenciado cataclismos y luchas de razas,

por algo estás presente en los sueños del

por algo eres el ave que han buscado los fuertes imperios.

En el poema "A un pintor" de la serie "Lira alerta" de El canto errante el hablante poético dice al "Pintor de melancolías" "deja esa visión" pues "Hay soles de eternos días", acudiendo así a la imagen del sol como figura que simboliza inmortalidad e inteligencia cósmica. Este hablante lírico, que alienta al pintor a vivir el momento, ha percibido previamente las imágenes del pintor como señales apocalípticas: Hondas negruras de abismo/ y espanto fatal, / lividez de cataclismo/ o anuncio mortal. En la siguiente estrofa el hablante interioriza tanto las señales que hasta se siente amedrentado: Ráfagas de sombra y frío/ y un errante ir... / ( $V a$ Vamos a morir, Dios mío, / vamos a morir!

En el poema "Agencia" de El canto errante el enunciador lírico reacentúa el discurso del profeta Malaquías cuando se refiere a ciertas señales apocalípticas: ${ }^{6}$

París se flagela de placer.

Un cometa va a aparecer.

Se cumplen ya las profecías

Del viejo monje Malaquías. 
Después de expresar indicios de que todo va mal en distintas partes del mundo, el hablante refiere cómo se han ido desvirtuando los valores, incluso da muestras de este deterioro mediante distintos factores: la pederastia, la pérdida de fe, la cuestión del poder político y religioso, el orden moral y el imaginario colectivo: ${ }^{7}$
Se organizará por un bill
la prostitución infantil.
La fe blanca se desvirtúa
y todo negro continúa.
En alguna parte está
el palacio del Anticristo.
Se cambian comunicaciones
entre lesbianas y gitones.
Se anuncia que viene el Judío
errante... ¿Hay algo más Dios mío?...

En este poema el enunciador individual a modo de lamento, se dirige al enunciatario aludido en el último verso. En el poema "Santa Elena de Montenegro" de la sección "Varia" del Poema del otoño y otros poemas encontramos al enunciador con una percepción social y religiosa, que asocia reminiscencias de terror, hambre y desamparo como si se tratara de la vida en plena Edad Media. De esta impresión emerge el discurso apocalíptico. En primer plano, surge la situación de emergencia que vive un conglomerado de personas afectadas por un fuerte terremoto, y que a modo de convulsión cósmica, es testimoniada así: Pasan furias haciendo gestos, / pasan mil rostros descompuestos. ${ }^{8}$. Pero este testimonio va a corresponder a la instancia de alguien capaz de percibir las señales: allá arriba hay signos funestos. De esta manera el enunciador considera imperativa la justicia: Falta la terrible trompeta dirá. Incluso, este hablante interioriza en mayor grado el evento (Mas oye el alma del poeta/ crujir los huesos del planeta), semejante al juicio final (Van rebaños dolientes... van/visiones de duelo y afán/ cual vio en su apocalipsis Juan).

Se cumple, por tanto, la analogía entre el enunciador poético (profeta) y el evento terráqueo (la conciencia humana).

En el poema "¡Pax!" de la "Selección de textos dispersos" de Poesías, leído por Darío en su proyecto pacificador al pasar por Estados Unidos en 1915, escribe acerca de que el mal social y político, las guerras injustas y el progreso (aplicado incorrectamente), tendrán su momento crítico, situación que, no obstante, será para la restauración, según el enunciador atribulado:

6 Se refiere a las profecías atribuidas al arzobispo San Malaquías de Armagh (10941148) pero fueron publicadas siglos después (1595 y 1690), cuando los eventos ya habían sucedido.

7 La alusión al Judío Errante en los últimos dos versos del poema, proviene del imaginario colectivo que origina esta leyenda o texto cultural, pero que tiene su origen en un pasaje bíblico cuando el personaje ofendió a Cristo camino a su crucifixión. 8 La cifra "mil", que en lenguaje bíblico significa muchedumbre, es muchedumbre sufriente, inmersa en un dramatismo singular. 


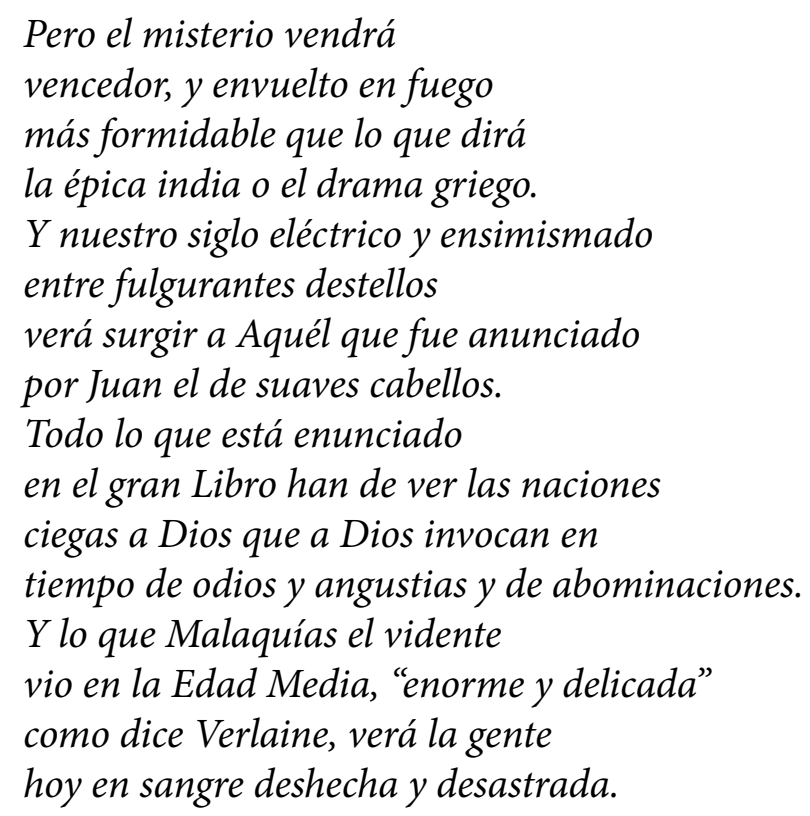

En este fragmento, saturado de elementos simbólicos, el evento concreto, presumiblemente nunca registrado por la historia ni la cultura, se presenta dimensionado. Pero esta imagen de convulsión cósmica no será otra que la del "siglo eléctrico". Es decir, el de la modernidad industrial y capitalista, que ha hecho méritos para presenciar y ser parte misma del apocalipsis. Aquí los indicios corresponden tanto a la paz, como a la fe y a la justicia. En consecuencia, el hablante poético dirá que (....) Jesucristo no está muerto/ y contra el homicidio, el odio, el robo/ Él es la Luz, el Camino y la Vida. En este texto el enunciador iterativo acude a la imagen apocalíptica para persuadir al hombre acerca de su conducta, que de no modificarla le caerá la maldición::

Si la paz no es posible, que como en Isaías

las ciudades revienten.

Que sean de tinieblas las noches y los días;

que las almas que sienten

soplo de Dios, duerman sueño profundo

mientras que se desangra y se deshace el mundo.

Y que cuando del apocalíptico enigma

surja el caballo blanco, con resplandor y estigma,

los únicos que se hundan en la santa Verdad

sean los puros hombres de buena voluntad

que entre las zarzas ásperas de este vivir han visto

las huellas de los pasos de Nuestro Padre Cristo. 


\section{CONCLUSIONES}

Hemos expuesto hasta aquí cómo Rubén Darío formula la visión que tiene sobre los problemas mundiales, continentales o simplemente humanos, acudiendo a un enunciador poético que se ve atribulado ante el imperativo de revelar tales imágenes. Este enunciador, depositario de la conciencia crítica, logra un estatus de comunicación con Dios; como tendencia del discurso poético se presenta ante el enunciatario bíblico (Jesucristo o Dios), otras veces es ante la figura colectiva (América Latina o América Hispana) y en menor frecuencia ante figuras de la historia y la cultura. Su pretensión es enunciar la necesidad de una toma de conciencia de la crisis que atraviesa la sociedad del momento, en situaciones específicas.

El empeño de Rubén Darío por la actualización del discurso apocalíptico lo lleva a proponer variantes del enunciador literario, sean estas jerárquicas o de acentuación emotiva, ideológica e hispanista. Esta aplicación paradigmática del discurso bíblico, asimismo, funciona no sólo como estrategia del autor por enriquecer las distintas posibilidades semánticas y expresivas de la interioridad del texto, sino también como una exteriorización de la angustia colectiva y personal, y la necesidad de confiar en Dios y en la historia. Entre tanto, el corpus de fragmentos en que se ha basado este trabajo, queda como una macroestructura en la que se desarrolla el tema axiológico de una nueva sociedad con valores constructivos. 
Blanco, D. (2004). Autor, enunciador, narrador. En Lienzo, Revista de la Universidad de Lima, $N^{\circ} 25,9-26$.

Chevalier, J. (1986). Diccionario de los símbolos. Barcelona: Herder

Cirlot, J. E. (2006). Diccionario de símbolos. Madrid: Ediciones Siruela.

Darío, R. (1988). Historia de mis libros. Managua: Nueva Nicaragua.

Darío, R. (1989). Poesía. Ciudad de la Habana: Editorial Arte y Literatura.

Darío, R. (1994). Cuentos completos. Managua: Nueva Nicaragua.

Fabry, G. (2012). "El imaginario apocalíptico en la literatura hispanoamericana: esbozo de una tipología. En Cuadernos Líricos. $N^{\circ} 7$. Versión electrónica consultada en febrero de 2015 en http://lirico.revues.org/689

Frye, N. (1988). El Gran Código. Una lectura mitológica y literaria de la Biblia. Barcelona: Gedisa.

Gutiérrez, G. R. (2004). Supuestos históricos y culturales. Bogotá: Fondo de Cultura Económica.

Lindón, A. (2007). Diálogo con Néstor García Canclini. ¿Qué son los imaginarios y cómo actúan en la ciudad? (Entrevista). En Revista Eure Vol. XXXIII, No 99 (89-99). Versión electrónica. Extraído el 16-2-2016 en http://www.scielo.cl/pdf/eure/v33n99/art08.pdf

Pastor García, R. (1996). Lo que está a punto de suceder. Introducción al Apocalipsis. salamanca: Estudio Teológico de San Ildefonso.

Paz, O. (1991). Cuadrivio. Barcelona: Biblioteca de bolsillo.

Ros, W. (1992). Nuestro imaginario cultural. Simbólica literaria hispanoamericana. Barcelona: Anthropos.

Ruiz Barrionuevo, C. (2002). Rubén Darío. Madrid: Síntesis. 